\title{
Effects of Particle Size on Mechanical Properties of a TiC Containing Tool Steel by Hot Isostatic Press
}

\author{
Jhewn-Kuang Chen ${ }^{1}$, Tzu-Piao Tang ${ }^{1}$, Sen-Fu Chan ${ }^{1}$ and Shih-Hsien Chang ${ }^{2}$ \\ ${ }^{1}$ Department of Materials and Mineral Resources Engineering, National Taipei University of Technology, \\ Taipei 106, Taiwan, R.O. China \\ ${ }^{2}$ ASSAB Steel Taiwan, Taipei 248, Taiwan, R.O. China
}

0-25 mass $\%$ of $\sim 2$ um and $\sim 20$ um TiC powders are added to vanadium and chromium containing steel powders to form metal matrix composite tool steels. The metal and ceramic powders are encapsulated and hot isostatically pressed for densification. Their density and mechanical properties are characterized. Product densification of over 99.9\% theoretical density is achieved. Its hardness is found to increase with the amount of TiC addition. Product with over HRc65 hardness is obtained with addition of 25 mass $\%$ coarse TiC particles in which the matrix and strengthening particles intermix uniformly. The fine TiC particles distributed as packs at the intergranular regions of the matrix phase and give less hardening effects. The flexural strength is reduced by $\mathrm{TiC}$ addition regardless of TiC particle size, because the flexural strength is controlled mainly by crack initiation and less by crack propagation. For impact test, brittle fracture is induced by high strain rate which initiates the cracks with ease in both matrix and hard phases. The impact toughness is thus increased slightly with TiC showing fine particles are more effective in blocking crack tip propagation in high strain rate testing condition. [doi:10.2320/matertrans.MER2007262]

(Received October 31, 2007; Accepted December 17, 2007; Published February 6, 2008)

Keywords: metal matrix composite, hot isostatic press, titanium carbide, tool steel, mechanical properties, brittle fracture

\section{Introduction}

TiC-strengthened tool steel has since 1970s been characterized for good combined thermal stability and mechanical properties. $^{1)}$ Many products, such as FERROTiC ${ }^{\mathrm{TM}}$, TiCALLOY $^{\mathrm{TM}}$, and FERRO-TITANIT ${ }^{\mathrm{TM}}$, have been developed and commercialized. ${ }^{2)}$ Common processing routes for making TiC-strengthened steels include: powder metallurgy, conventional melting and casting, and in-situ production of dispersoids, ${ }^{3)}$ etc. Among these, powder metallurgy by hot isostatic pressing $\left(\mathrm{HIP}^{4)}\right)$ has been most widely adopted. ${ }^{5,6}$ Up to $45 \mathrm{vol} \%$ of $\mathrm{TiC}$ can be embedded in high alloy steel matrix to manufacture steel with hardness up to HRc70. ${ }^{7)}$

In plastic injection molding industry, for example, the stronger mold materials are needed in order to manufacture stronger engineering plastics. ${ }^{8)}$ Vanadium and chromium containing composite tool steels are developed to meet the needs for improved corrosion and wear resistance. ${ }^{9)}$ The combination of $\mathrm{TiC}$ and vanadium and chromium containing tool steel provides a fair solution for prolonged tool life and reduced maintenance cost.

Intuitively, finer strengthening particles give rise to larger strengthening effects. This interpretation is based upon the assumption that the particles are dispersed uniformly in reduced spacing. The fine particles act as barriers for dislocation migration. In engineering applications, very fine particles may not be preferred due to consideration of cost and difficulty of powder handling.

It is of interest to look into how ratio of matrix and strengthening particle size affects mechanical behaviors in industrial HIPped composite products. In this study, effects of TiC fraction and paritcle size upon mechanical properties of composite tool steels are investigated. Their hardness, flexural strength, and impact energy are characterized.

\section{Experimental Procedure}

The matrix tool steel powders were manufactured by
Table 1 Composition (mass\%) of matrix tool steel powders used in this study.

\begin{tabular}{cccccc}
\hline $\mathrm{C}$ & $\mathrm{Si}$ & $\mathrm{Mn}$ & $\mathrm{Cr}$ & $\mathrm{Mo}$ & $\mathrm{V}$ \\
\hline 1.7 & 0.8 & 0.3 & 18 & 1 & 3 \\
\hline
\end{tabular}

Table 2 Density and mechanical properties of composite tool steel with different TiC sizes and additions.

\begin{tabular}{ccccc}
\hline mass\% TiC & 0 & 5 & 10 & 25 \\
\hline Equivalent vol\% TiC & 0 & 7.5 & 14.6 & 33.9 \\
\hline TiC size, um & - & 2 & 2 & 20 \\
\hline Relative density, \% & 99.86 & 99.97 & 99.96 & 99.87 \\
\hline Porosity, \% & $0.14 \%$ & $0.03 \%$ & $0.04 \%$ & $0.13 \%$ \\
\hline Average hardness, $\mathrm{HRc}$ & 60.3 & 60.7 & 61.0 & 65.7 \\
\hline Average flexural strength, $\mathrm{MPa}$ & 3482 & 1461 & 1819 & 1209 \\
\hline Average impact energy, $\mathrm{J} / \mathrm{cm}^{2}$ & 8.8 & 20.2 & 21.1 & 13.1 \\
\hline
\end{tabular}

vacuum melting and inert gas atomization. The atomized powders were spherical in shape. The particle size ranged from 10 um to $100 \mathrm{um}$ according to SEM observation and laser particle size analysis. The composition of matrix powder was listed in Table 1 which contained 1.7 mass $\%$ of C, 18 mass $\%$ of chromium and 3 mass $\%$ of vanadium specifically for corrosion-resistant and strength-demanding applications.

Two different sizes of averagely 2 um and 20 um irregular shaped TiC particles were used as strengthening dispersoids to mix with matrix powders. $0,5,10$ mass $\%$ of 2 um and 25 mass $\%$ of 20 um TiC powders, corresponding to $0,7.5,15$, and $34 \mathrm{vol} \%$ strengthening phase fraction (Table 2), were mixed with matrix tool steel powders via ball milling. The mixtures of $\mathrm{TiC}$ and tool steel powders were canned in stainless steel at $<0.13 \mathrm{~Pa}$ vacuum before hot isostatic pressing process (HIP). The encapsulations were HIPped at $1250^{\circ} \mathrm{C}$ and $120 \mathrm{MPa}$ for $4 \mathrm{hrs}$ before furnace cooling. 
The bulk densities of the HIPped samples were measured by Archimedes method using distilled water as medium. The relative densities were defined as the measured density divided by an estimated theoretical density. The theoretical density was estimated using rule of mixture among the densities of $\mathrm{TiC}$ and steel assuming neither phase transformation nor reactions occurring after HIPping.

The HIPped specimens for three-point bending and impact tests were first machined by wire-EDM. The heat treatment was then performed by austenitizing the specimens at $1100^{\circ} \mathrm{C}$ for $1 \mathrm{~h}$, quenching in water, tempering twice at $480^{\circ} \mathrm{C}$ for $3 \mathrm{~h}$, and furnace cooled. The surfaces of heat treated samples were finished to final size using \#120 cubic BN grinding wheels before performing mechanical tests.

Specimen size for the bending test was $6 \times 5.5 \times 50 \mathrm{~mm}$ and its flexural strength, $\sigma_{\mathrm{fs}}$, was obtained using

$$
\sigma_{\mathrm{fs}}=\frac{3 F L}{2 b h^{2}}
$$

where $F$ was the force applied to fracture the specimen, $L=30 \mathrm{~mm}$ was the distance between two supports at lower side of the specimen, and $b=6 \mathrm{~mm}$ and $h=5.5 \mathrm{~mm}$ were the width and height of the specimen cross section, respectively. Impact energy was measured on $10 \times 10 \times$ $55 \mathrm{~mm}$ standard Charpy V-notch specimens. Five bending and five impact specimens were tested to obtain average values for each material.

The hardness was measured in HRc scale using $150 \mathrm{~kg}$ load via a diamond cone shaped indentation on flat and \#600 ground specimen surface. The size of indentation was in the order of millimeters and thus much larger than that of matrix and $\mathrm{TiC}$ particles. Six specimens for each material were tested to obtain average hardness.

The microstructures were observed on ground and polished specimens using optical microscope. The fractographs were made on freshly fractured specimen surfaces using a Hitachi S-4700 field emission scanning electron microscope (FESEM).

\section{Results and Discussion}

\subsection{Microstructure observation and density measure- ment}

Figure 1 shows the microstructures of $0,5,10$, and 25 mass\% TiC-tool steel composites. It is noted that for 5 and 10 mass $\%$ TiC samples, the fine TiC particles are distributed around the atomized spherical tool steel powders. Whereas in the case of 25 mass $\% \mathrm{TiC}$, the coarse TiC particles distribute uniformly among the steel matrix.

Since the fine $\mathrm{TiC}$ powders of average $2 \mathrm{um}$ in size are much smaller than that of tool steel powders, packs of TiC powders fill in the intergranular regions and result in Fig. 1(b) and (c) structures. It is expected that such filling benefits the reduction of porosity among powders. From geometrical point of view, this filling geometry can account for up to $30 \mathrm{vol} \%$ of total volume at the intergranular space. ${ }^{10)}$ The $30 \mathrm{vol} \%$ space corresponds to around $22 \mathrm{mass} \% \mathrm{TiC}$ addition. That is, if very fine $\mathrm{TiC}$ particles are added to fill the space among matrix particles, up to 22 mass $\%$ of $\mathrm{TiC}$ may be added.
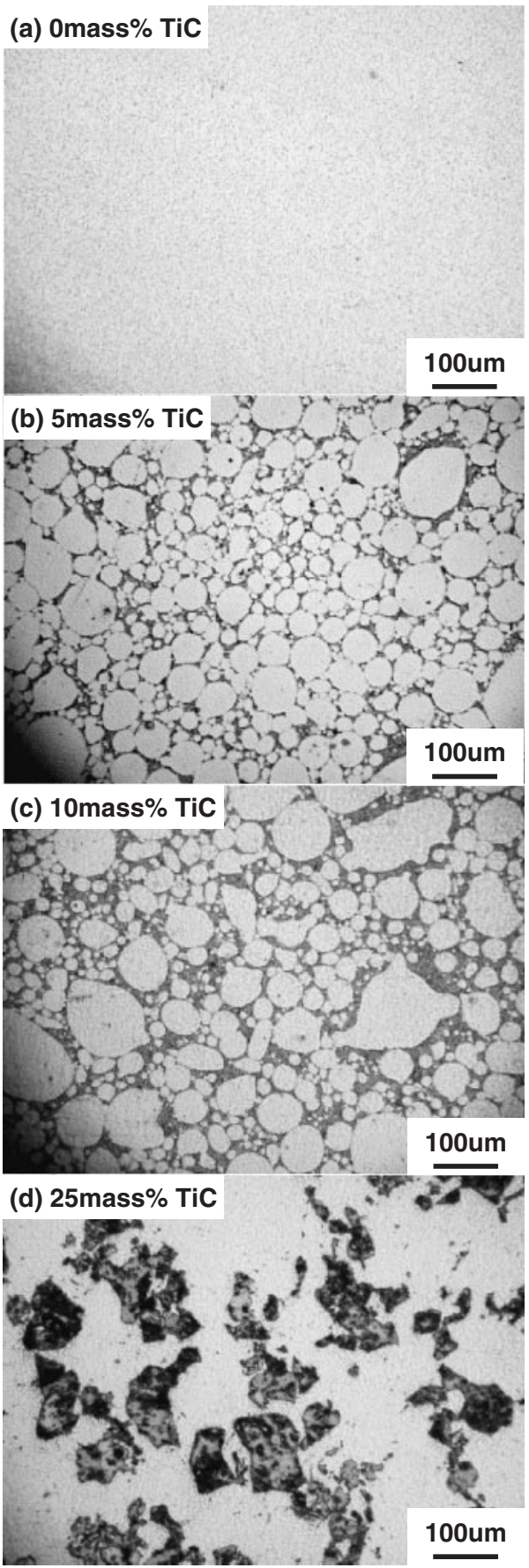

Fig. 1 Optical microstructures of composite tool steels containing (a) 0 , (b) 5, (c) 10, and (d) 25 mass $\%$ TiC.

On the other hand, in 25 mass $\%$ TiC specimen, $\mathrm{TiC}$ particle size is in the same order as those of matrix powders, therefore the structure is a uniform distribution of matrix and reinforcing phase. The presence of $\mathrm{TiC}$ is rather discontinuous in comparison with those by fine TiC particles. These observations are consistent with those reported by Pagounis et al. ${ }^{5)}$ that the distribution of reinforcing phase varies greatly with different sizes of the matrix and dispersoids.

The densities of the four specimens are listed in Table 2. It is shown that all HIPped specimens bear porosity of lower than $0.15 \%$. In the cases of 0 mass $\%$ and 25 mass $\% \mathrm{TiC}$ added specimens, it is noted that the composites with fine $\mathrm{TiC}$ particles have lower percentage of porosity under $0.05 \%$. 


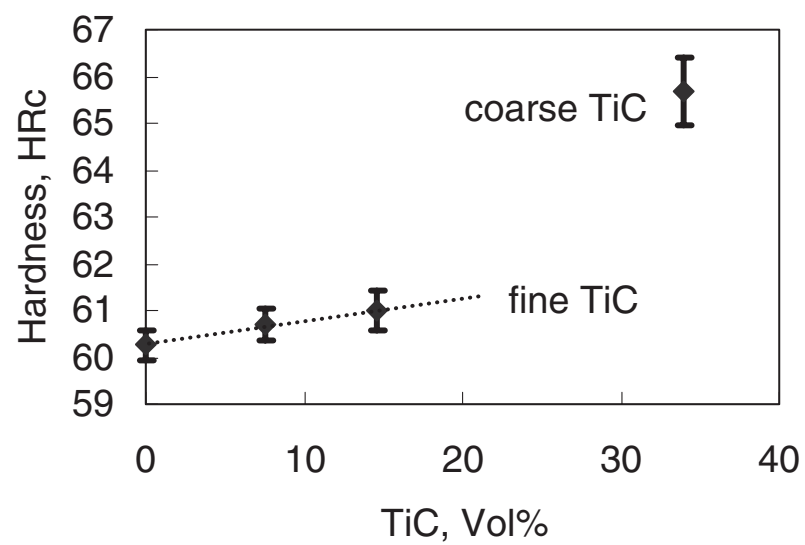

Fig. 2 Increase of hardness with TiC volume fraction.

This confirms that fine $\mathrm{TiC}$ particles are beneficial for densification as the fine particles fill in the intergranular regions of the matrix particles. On the other hand, the slightly higher porosity is formed in 25 mass $\%$ TiC added composite due to relatively equivalent particle size of the matrix and reinforcing phases.

\subsection{Hardness measurements}

In Table 2, the hardness of the specimens apparently increases with the percentage of $\mathrm{TiC}$ addition. Further observation on hardness vs. TiC volume fraction plot shows that the increase of hardness separates into two classes by fine and coarse TiC as shown in Fig. 2.

According to reference 1) and 2), the yield strength and hardness of metal matrix composites both increases linearly with volume fraction of the hard phase. However, in Fig. 2, the four composites are clearly not linearly arranged. Instead, two separate trends can be observed.

In composites hardened by fine $\mathrm{TiC}$ particles (5 and 10 mass $\%$ or 7.5 and 14.6 vol\% TiC added specimens), their hardness indeed increase linearly with $\mathrm{TiC}$ volume fraction. However, the composite hardened by coarse $\mathrm{TiC}$ particles ( 25 mass\% or $34 \mathrm{vol} \% \mathrm{TiC}$ ) shows much higher hardening effects to the composites than the fine TiC particles.

This is, at first sight, in contrary to the knowledge of dispersive strengthening mechanism that fine particles are more effective reinforcements. However, such mechanism is based upon the assumption that fine reinforcing particles are uniformly distributed in matrix. In current study, the fine TiC particles fill as packs at the intergranular regions as demonstrated in Fig. 1. Such particle distribution greatly increases the inter-pack spacing. It thus gives a lessened effect on the hardness of composite. The fine particle distribution geometry becomes equivalence of a smaller addition of coarse $\mathrm{TiC}$ particles (or packs of fine $\mathrm{TiC}$ ) in hardness test. Therefore, the increase of hardness is relatively small for composites with additions of 5 and 10 mass $\%$ fine TiC particles.

On the other hand, in 25 mass\% TiC added specimen, the similar matrix and $\mathrm{TiC}$ particle size allows the hard phase to distribute at a more uniform geometrical arrangement close to that described by dispersive strengthening mechanism. The hardness is as high as $65.7 \mathrm{HRc}$ demonstrating better hardening effect.

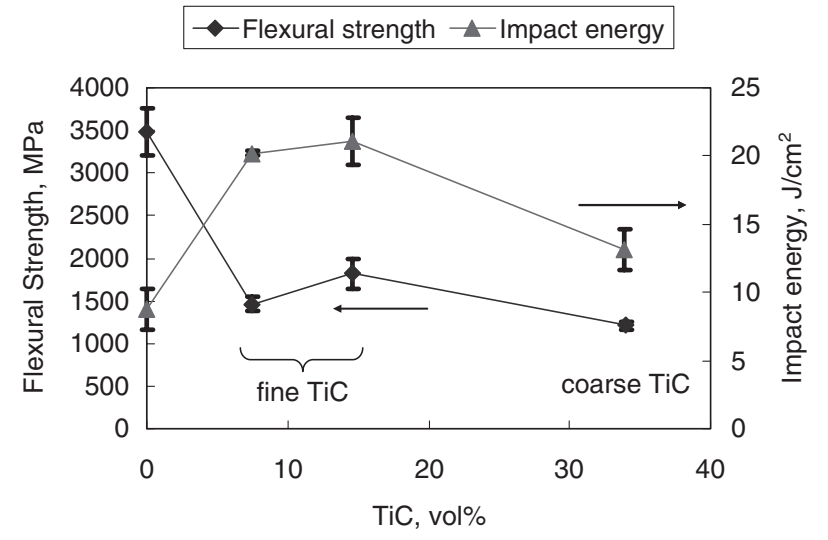

Fig. 3 Changes of flexural strength and impact energy with TiC volume fraction.

These observations further imply that, for the same percentage of reinforcing particles, the hardening effect depends on not only the hard particle size but also the ratio of the matrix and the second phase particle sizes in powder metallurgy processes without liquid phase sintering. Higher hardness can be achieved in cases where the sizes of matrix and hard particles are in similar scale. In the case where very fine reinforcing particles are added, the particles fall into intergranular regions and reduce their hardening effects on composites. Such factors give rise to very different effects on the hardness of composites as shown in Fig. 2.

\subsection{Flexural strength measurements}

The flexural strength drops from $3482 \mathrm{MPa}$ without TiC addition to below $2000 \mathrm{MPa}$ with $\mathrm{TiC}$ addition as shown in Fig. 3. The great drop in flexural strength indicates changes in fracture modes when TiC is added. It is observed from the fractographs (Fig. 4) that the dimple size increases in $\mathrm{TiC}$ added samples. The dimple size is below $1 \mathrm{um}$ in the non-TiC specimen, whereas the fractured feature size becomes over 2 um in 5 and 10 mass $\%$ fine TiC added samples. The fracture feature size further increases to over 20 um in 25 mass $\%$ coarse $\mathrm{TiC}$ added specimen. The sizes of fracture features apparently coincide with $\mathrm{TiC}$ particle sizes. The cleavage is clearly revealed on $\mathrm{TiC}$ particles. The changes of fine dimples into cleavages on fracture surface demonstrate obvious ductile-brittle transition due to presence of $\mathrm{TiC}$ particles.

Even though there is a difference in the amount of $\mathrm{TiC}$ addition, the difference of flexural strengths in 5, 10, and 25 mass \% TiC samples is rather small. This suggests that once the fracture tips are initiated, the fracture propagation is relatively easy in passing $\mathrm{TiC}$ particles. Or the flexural strength is controlled by crack initiation process, and the amount of $\mathrm{TiC}$ does not affect the flexural strength greatly in $\mathrm{TiC}$ containing composites. The fractographs of TiC added composites are thus characterized by TiC cleavages in Fig. 4.

Although the difference is small, the composite with 10 mass $\%$ of fine TiC particles shows slightly higher flexural strength than 5 mass $\%$ TiC containing composites. It suggests that more $\mathrm{TiC}$ particles can still increase the resistance to crack propagation slightly in bending tests. On the other hand, the 25 mass $\%$ coarse TiC containing sample has the 

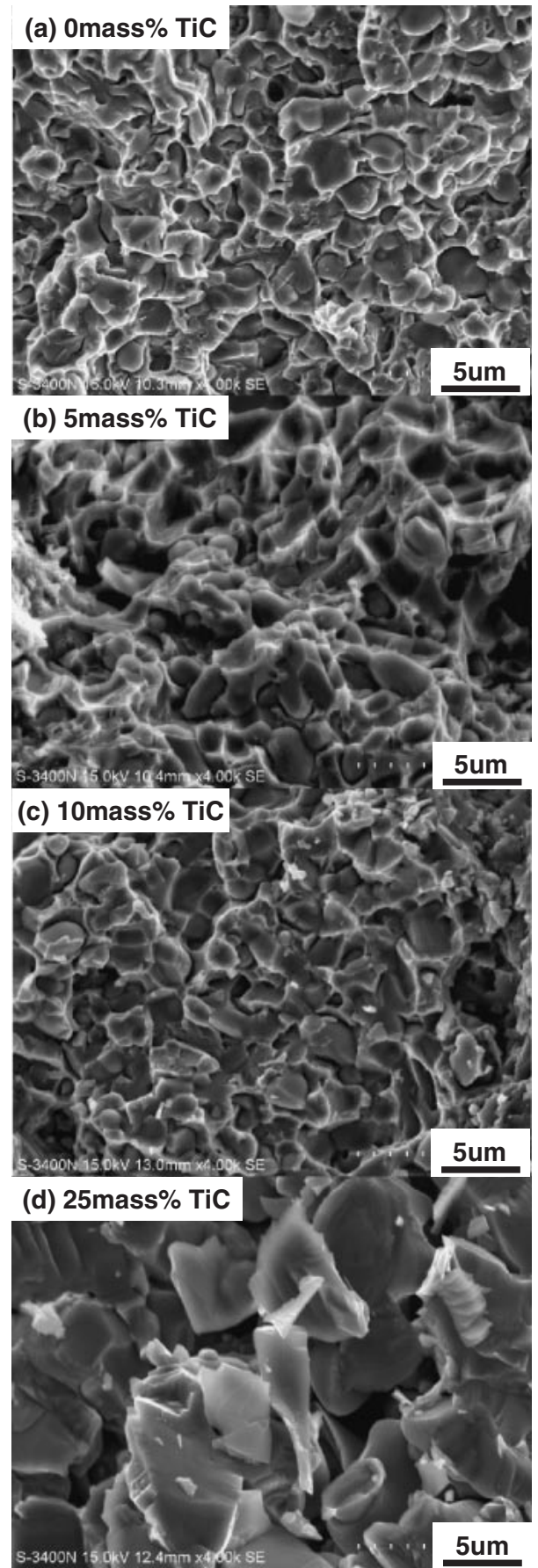

Fig. 4 Fracture surfaces of three point bending test specimens containing (a) 0 , (b) 5 , (c) 10 , and (d) 25 mass $\%$ TiC.

lowest flexural strength of all. It may be explained by Brechet et $a l .{ }^{11)}$ that larger particles also have tendency for earlier cracking initiation. Therefore, fine $\mathrm{TiC}$ particles are slightly more effective in resisting local crack propagation due to increased number of hard phase barriers.

\subsection{Impact energy measurements}

Figure 3 shows that the impact energies increase with $\mathrm{TiC}$ for 5 and 10 mass $\%$ specimens but drops for 25 mass $\%$ TiC specimens. The impact energies of all samples are lower than $22 \mathrm{~J} / \mathrm{cm}^{2}$. The low impact energies indicate brittle fracture characteristics for all materials currently studied. SEM fractographs in Fig. 5 show cleavage features in all materials
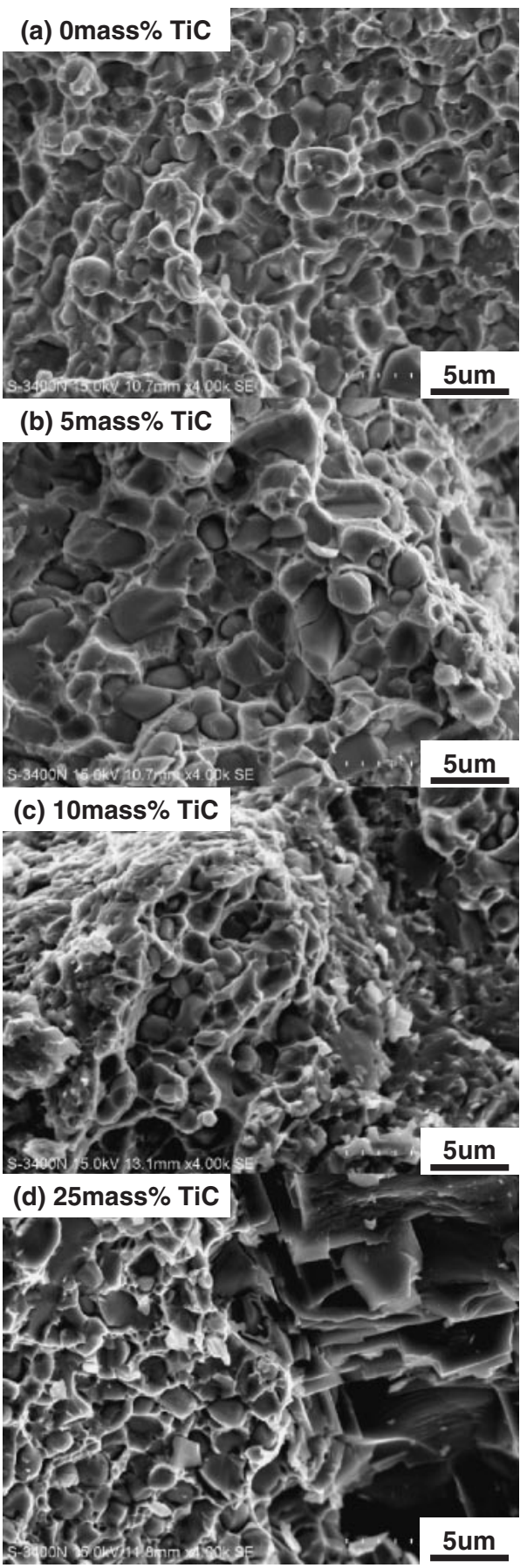

Fig. 5 Fracture surfaces of Charpy impact test specimens containing (a) 0 , (b) 5 , (c) 10 , and (d) 25 mass $\%$ TiC.

and confirm the brittle fracture behaviors. Specifically, at right hand side of Fig. 5(d), large cleavaged TiC surfaces are revealed in comparison with the fine matrix fracture surface at left hand side.

The higher impact energies of 5 and 10 mass $\%$ TiC specimens (Fig. 3) than non TiC-added steel indicate that fine TiC particles have very different effects on impact energy compared to their effects on hardness and flexural strength. As both the matrix and the second phases demonstrate brittle fracture, the cracks are initiated with the same ease for both phases in the impact test under high strain rate condition.

It is reported by Kroon and Faleskog ${ }^{12)}$ that plastic rate has a significant effect on ductile-brittle transition. Because the 
brittleness and crack initiation is induced by the high strain rate, the impact test may become crack propagation controlled. The impact energy would then depend on the total crack propagation resistance across fracture area.

When TiC particle size decreases, the number of particles and total crack propagation areas across $\mathrm{TiC}$ particles increase. The total crack propagation area across $\mathrm{TiC}$ particles is inversely proportional to the size of TiC particles. The 5 and 10 mass $\%$ fine TiC containing samples can thus bear higher impact energies than 0 and 25 mass $\%$ TiC added materials due to increase of resistance for crack propagation.

It is further observed that 25 mass $\%$ coarse TiC added composite shows higher impact energy than non-TiC added material. Coarse $\mathrm{TiC}$ particles, though not as many as fine TiC particles in numbers, can still increase the resistance to crack propagation. This further confirms that the crack fracture across $\mathrm{TiC}$ must have positive effects on the increase of impact energy.

\section{Conclusion}

Effects of TiC fraction and size on a corrosion-resistant composite tool steel are presented in this study. It is shown that the hardness of composite increases with TiC additions. Besides the volume fraction of $\mathrm{TiC}$ hard phase, the size and distributions of $\mathrm{TiC}$ particles also affect the mechanical properties of composites greatly.

Fine TiC particles distribute as packs at intergranular regions of matrix phase to reduce packing porosity, whereas the coarse TiC particles distribute uniformly among matrix phase. The distribution of fine TiC particle packs is similar to large $\mathrm{TiC}$ particles distributed at larger spacing, therefore the increase of hardness is not as much as that provided by coarse TiC particles. Ratio of matrix and dispersoid particle size apparently plays an important role in hardness performance.

TiC induces brittle fracture behaviors for three-point bending tests. Flexural strength drops greatly due to TiC additions. Crack propagation appears to be relatively easy in bending $\mathrm{TiC}$ added composite, therefore the flexural strengths are not affected greatly by amount of TiC added.

For impact tests, both matrix and hard phases demonstrate brittle fracture, therefore even non-TiC added tool steel bears low impact energy. Addition of fine TiC particles increases the impact energies more effectively than coarse particles indicating their role in barricading crack tip propagation for high strain rate condition such as impact test.

\section{Acknowledgement}

The authors would like to express their appreciation for financial support of ASSAB Steel Taiwan and National Science Council of Taiwan under grant \#NSC95-2622-E027-003-CC3.

\section{REFERENCES}

1) K. I. Parashivamurthy, R. K. Kumar, S. Seetharamu and M. N. Chandrasekharaiah: J. Mater. Sci. 36 (2001) 4519-4530.

2) B. S. Terry and O. S. Chinyamakobvu: J. Mater. Sci. Lett. 10 (1991) $628-629$.

3) K. Das, T. K. Bandyopadhyay and S. Das: J. Mater. Sci. 37 (2002) 3881-3892.

4) I. A. Ibrahim, F. A. Mohamed and E. J. Lavernia: J. Mater. Sci. 26 (1991) 1137-1156.

5) E. Pagounis and V. K. Lindroos: Materials Science and Engineering A 246 (1998) 221-234.

6) E. Pagounis, M. Talvitie and V. K. Lindroos: Powder Metall. 40 (1997) 55-61.

7) M. Foller and H. Meyer: Proceedings on the 6th Intn'1 Conf. on Tooling, Sweden, 10-13 Sep. (2002).

8) O. Ozturk, O. Onmus and D. L. Williamson: Surface \& Coatings Technology 196 (2005) 333-340.

9) K. E. Pinnow, W. Stasko, J. J. Hauser and R. B. Doxon: Advances in Powder Metallurgy 6 (1992) 281-294.

10) E. Pagounis, M. Talvitie and V. K. Lindroos: Mater. Res. Bull. 3 (1996) 1277-1285.

11) Y. Brechet, J. D. Embury, S. Tao and L. Luo: Acta Metall. Mater. 39 (1991) 1781-1786.

12) M. Kroon and J. Faleskog: J. Mechanics \& Physics of Solids 53 (2005) 171-196. 